\title{
The System for Developing New Products at a Machine-building Enterprise Using System Engineering Techniques (For Example, PJSC MZIK)
}

\section{A.Yu. Solopov}

PJSC "Machine-building plant named after M.I. Kalinina ", Russia, 620017, Ekaterinburg, st. Cosmonauts Avenue, 18

\section{Annotation}

This article describes the problem of the task of finding and developing a new product in the conditions of a machine-building enterprise, as well as the vision of solving this problem (organization of works on search of ideas and development of a new product within the life cycle of the product at the machine-building plant named after M.I. Kinin). The picture of the task as a whole - on creation of an effective system of product support according to the life cycle is described. Technical and project processes are

Corresponding Author:

A.Yu. Solopov

solopov.aleksey@gmail.com

Received: 5 March 2020

Accepted: 18 March 2020

Published: 8 April 2020

Publishing services provided by Knowledge E

(c) A.Yu. Solopov. This article is distributed under the terms of the Creative Commons

Attribution License, which permits unrestricted use and redistribution provided that the original author and source are credited.

Selection and Peer-review under the responsibility of the SEC 2019 Conference Committee.

\section{Introduction}

The organization of the product life cycle existing at the plant (see Fig. 1) is actually poorly formalized, in particular, the stages "Search for a new product idea" (or "Idea") and "Development" based on standards GOST 15.201 [1], GOST 15.301 [2] and ensuing enterprise standards showed poor performance. This was revealed during the implementation of recent projects, using the latest developments as an example: the volume of requirements that did not fall into the technical specifications for development, and, as a result, the volume of improvements to products in serial production was critical for realizing the need for change. These problems were manifested in connection with an increase in the volume of development and an insufficient description of methods and practices in key areas, and often their absence. In particular, a description of the methods for collecting and analyzing requirements, tracing these requirements into the design and verifying them, working with feedback, and some others.

It is obvious that in order to ensure the development efficiency, minimize losses during implementation in mass production and eliminate (minimize) the risks of redesigning, it is 


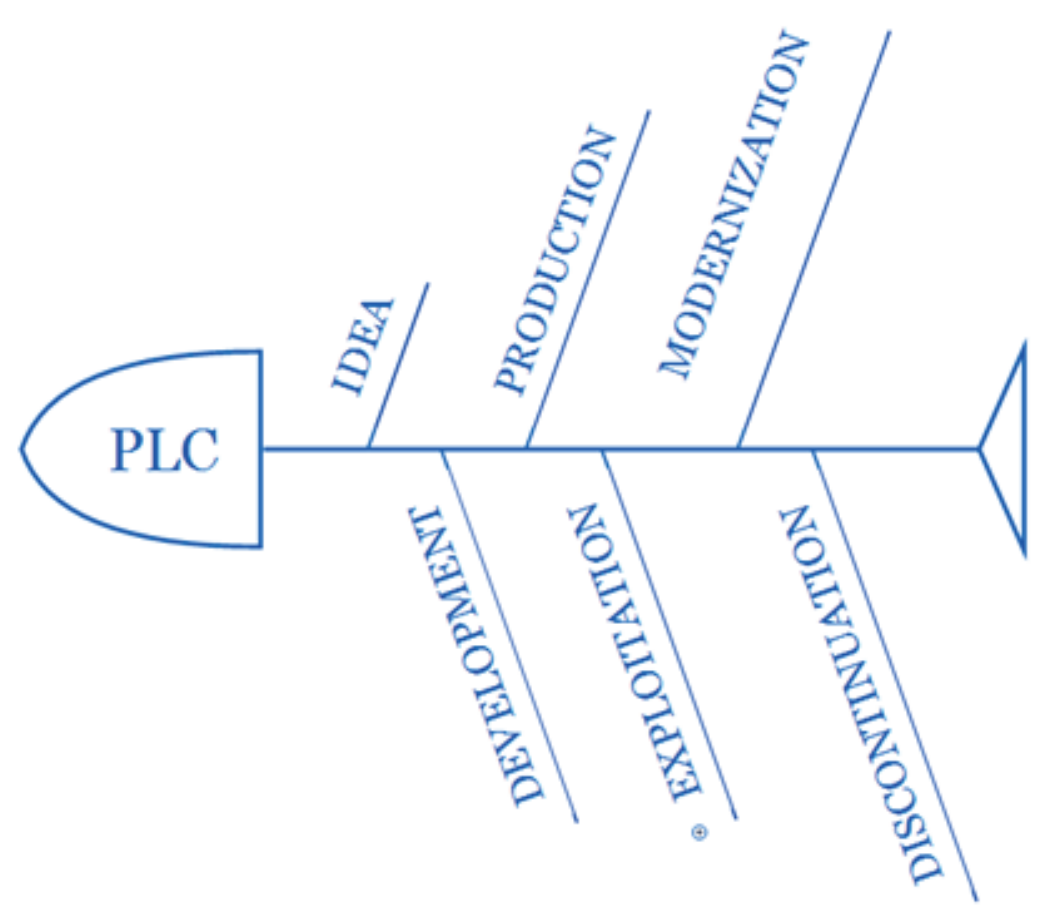

Figure 1: Product Life Cycle (PLC)

necessary to introduce a new system, taking into account the accumulated experience, based on GOST and standards [1-4] using modern methods of collecting, accounting and analyzing requirements, calculating the cost of a project, tracing requirements in a design, verifying and validating requirements in a final product. As well as techniques to effectively accompany the product through the life cycle. Undoubtedly, the key point in the work on the new standards will be the development of appropriate competencies among employees and monitoring compliance with these standards.

\subsection{Task description}

It is necessary to create two subsystems (two stages) of the product's life cycle: "Idea" and "Development" (to describe using standard all the necessary sub-steps, actions, methods, practices, identify those responsible, designate reference points and their control).

To complete this task, it is necessary to understand and formalize the remaining steps PLC (interfaces, artifacts, reference points). PLC will be the target system. This system should include a description based on ISO 15288 [4].

In this article we will consider the first two stages PLC: «ldea» $U$ «Development» Input for the first stage PLC - «Idea» will be the same as the input for the PLC (as the target 
system). These are the requirements of top-level stakeholders: the general director of the plant and his deputies; shareholders of the plant; Concern (of which the plant is a part); Ministry of Industry and Trade of the Russian Federation. One of the key conditions for choosing a new product is an adequate assessment of the competencies of the enterprise (conditionally readiness for a particular new product / area). Unfortunately, this stage is traditionally given the least time, but the success of a new project depends on the correctness of its implementation.

Stage «Idea» consists of several sub-steps.

First sub-step - product definition (or choice). During this sub-step it is necessary, based on the competencies of the enterprise, the requirements of top-level stakeholders, as well as taking into account other possible factors, using decision-making methods, determine a promising product. Responsible in the sub-stage experts from the sales and marketing department, top management of the plant, project management department, experts from other departments are invited if necessary.

Next is the sub-step collecting requirements - formalized at the exit technical task. During this sub-step, the study of analogues (preferably in operation), analysis of product usage scenarios, data collection from mandatory and recommended standards, preparation of technical and other requirements. Responsible for the sub-stage - marketing department specialists, requirements engineer, leading designer in the direction.

Next is the sub-step technical study product - at the exit a technical project, data for a feasibility study. It includes determining the external appearance of the product, developing a generalized layout of the product and the estimated complexity of the development and manufacturing, conducting basic power and other necessary engineering calculations, determining the main components, developing suppliers. Responsible for the sub-stage - requirements engineer, leading designer in the direction (if necessary, additional participants from the design and technological services are invited), project designer, configuration department.

The final sub-step will be feasibility study (analysis of the cost of the product, payback period, etc.), based on this analysis, the plant management at the scientific and technical council makes a decision on the appropriateness of continuing work on this project. Responsible for the sub-stage: project management department, sales department, top management of the plant.

In general, the output of the "Idea" stage (respectively, the input for the "Development" stage) is: a formalized technical task for development; outline sketch; feasibility study of the project; confirmed economic viability of development. 
There is also a vision that before the end of the creation of the plant's product portfolio (product line), the "Idea" stage will work permanently, searching for new promising products non-stop (with different intensities). This is due to the fact that, from the point of view of top-level stakeholders (plant management, group management), there are only one requirements for the product being developed - the product should be profitable.

The "Development" stage is divided into the following sub-stages:

1. release of design documentation for the manufacture of a prototype;

2. production of a prototype product;

3. preliminary tests of the prototype;

4. adjustment of design documentation and prototype;

5. test operation;

6. acceptance tests.

The first sub-step: all necessary calculations (additionally or due to changes in the development process), development of the 3D design, determination of the complete list of purchased components, formalization of the product operation algorithm, development of control software, writing test programs (design verification). Responsible for the sub-stage: design department, plant services.

The second sub-step: the acquisition of purchased components, the manufacture of parts of its own production, the assembly of prototypes, the adjustment of a prototype, development of the product operation algorithm, debugging of control software, preparation for testing. Responsible for the sub-stage: picking department, production, pilot production.

The third stage: conducting tests according to the relevant programs, determining the conformity of the prototype to the initial requirements. Responsible for the sub-stage: reliability and testing department, design department.

Fourth sub-step: adjustment of design documentation based on the results of assembly and testing, finalization of the prototype (if necessary). Responsible for the sub-stage: design department, plant services.

Fifth sub-step: conducting test operation - operating an un-certified product with the aim of validating the decisions made, obtaining first feedback from the operation (if necessary, repeat the fourth sub-step based on the results of this stage). Responsible for the sub-stage: reliability and testing department, design department. 
Sixth sub-step: conducting acceptance tests according to the corresponding program, determining the readiness of the product for the manufacture of the installation batch. Responsible for the sub-step: acceptance committee.

At the exit of the "Development" stage, design documentation appears with the letter $\mathrm{O}_{1}$, ready to launch an installation batch of products, prototypes of the product that have passed the tests and confirmed the compliance of the developed product with the specified technical requirements.

Further, the stage of "mass production" or simply "production" comes into force.

At each stage of the life cycle, the standard [4] recommends organizing 25 processes or practices combined in 4 groups: organizational, design, technical, and procurement. The use of adapted techniques will increase the efficiency of product life cycle management. Let us consider in detail technical practices (see Fig. 2) and design practices (see Fig. 3), which we will limit ourselves to.

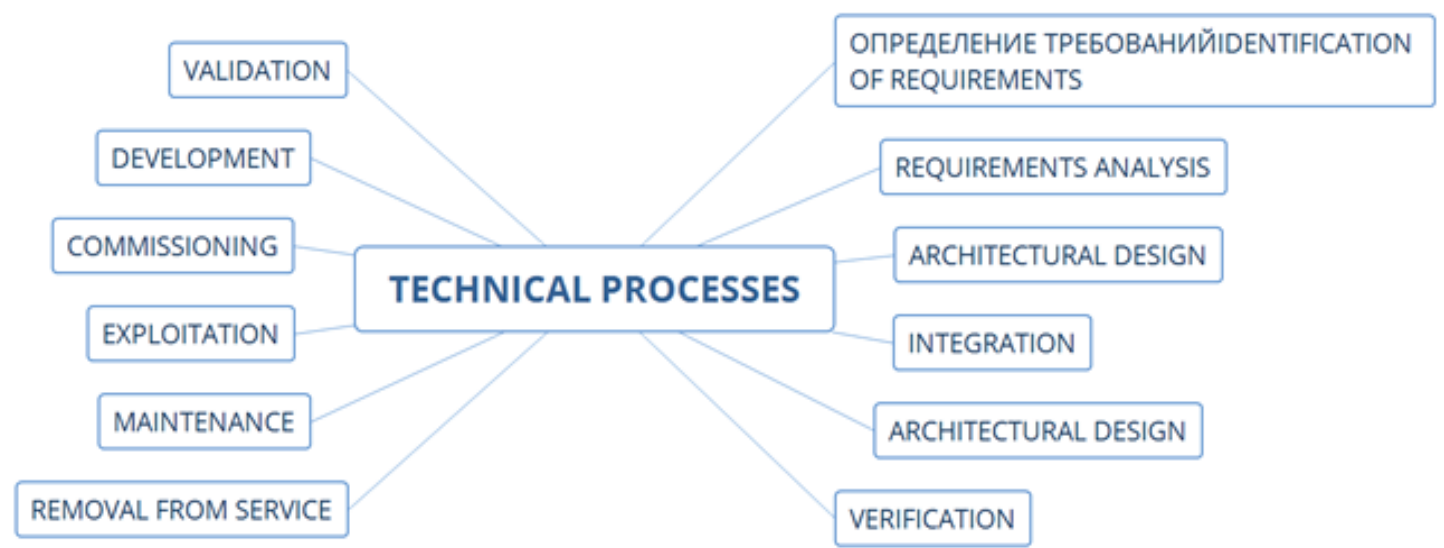

Figure 2: Technical processes (or practices) according ISO 15288

Once again, we note that the basic practice of technical processes is requirements management. This process, as it were, was ignored earlier, as it was reduced to the development of a technical task, after which it was forgotten. In fact, this is a living process that must go through all stages of the product life cycle and be the main tool for analyzing quality and improvement. All requirements must be analyzed. In the analysis of functional requirements, functional analysis comes to the fore as a tool for assessing the value of a future product [5].

In accordance with the standard [4], a minimum of actions should be organized on any project: team building, development of project management documentation (plans, schedules, etc.), development of a project development methodology (procedures, standards, regulations) and actions within developed procedures. At least 7 processes must be organized in this case (see Fig. 3). In addition to plans, the criteria for evaluating 
the project (measurement system) must be developed and the project must be evaluated and monitored. The investor is very interested in the risk analysis process, on the basis of which the decision-making process is organized [5].

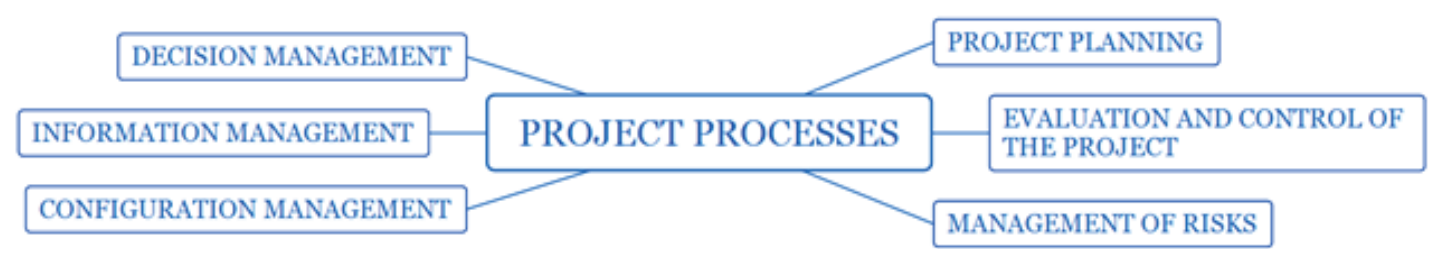

Figure 3: Design processes or practices

One of the key tasks is the use of software that provides work with system engineering artifacts, in particular, the application of work methods requirements. Specialized software requires significant implementation costs and mandatory staff training.

\section{Conclusion}

According to the author, the application of practices and techniques of system engineering adapted to the conditions of the enterprise PJSC MZIK at the stages of the product life cycle, as well as the availability of competent personnel and appropriate software, will reduce development costs. In general, this will simplify the process of diversification of production, will allow the company to reach a new level in the production of civilian products. This direction is a priority in the development strategy of the enterprise. In this connection, the topic is relevant.

\section{References}

[1] GOST R 15.201-2000 The system of development and putting products into production. Products for industrial purposes. The procedure for the development and putting products into production.

[2] GOST R 15.301-2016 The system of development and putting products into production. Products for industrial purposes. The procedure for the development and putting products into production.

[3] GOST R 15.000 The system of development and putting products into production. Key Points.

[4] GOST R ISO 15288-2005. Information technology. Systems Engineering Systems Life Cycle Processes. 
[5] Alexander Prosvirnov. Systems engineering - a myth or a key to efficiency. JSC VNIIIAES; "COST MANAGEMENT", US Department of Energy (DOE). Office of Administration, Budget and Evaluation (http://www.proatom.ru/modules.php?name= News\&file=article\&sid=3130). 